\title{
Driver Anger Scale (DAS) Among Car Drivers: How Serious Are They?
}

\author{
Kamarudin Ambak ${ }^{1, *}$, Shuhada Shamsudini ${ }^{1}$, Basil David Daniel ${ }^{1}$, and Ahmad Raqib Abd \\ Ghani $^{1}$ \\ ${ }^{1}$ Smart Driving Research Center, Faculty of Civil and Environmental Engineering, Universiti Tun \\ Hussein Onn Malaysia, 86400 Batu Pahat, Johor, Malaysia
}

\begin{abstract}
Nowadays, anger while driving on the road is a crucial issue in Malaysia. The anger of driver may lead to traffic crashes. Road accident issue is an important agenda in every country. Driver behaviour and attitude such as impatience, hasty and hot-tempered on the road has become one of the causes in road accidents. Uncontrolled anger will affect the behavior of oneself during driving and could cause an individual to display aggressive attitude. Therefore, this study is aimed to identify contributing factor in anger of drivers and evaluate the Driver Anger Scale (DAS) in Batu Pahat, Johor. In addition, this study also analyzes the relationship between driver anger and the factor of DAS. Cross sectional study method was conducted in this study by distributing 250 questionnaires to car drivers. The data collectied was analyzed by descriptive, chi-square test, correlation and regression analysis using Statistical Package for Social Sciences (SPSS) version 20.0. The findings show that the discourtesy was reported as the most dominant factor contributing to driver anger. As a recommendation, to overcome driver anger issue, the authorities should prepare an action plan, promote and nurture public to practice good driving behaviour. Moreover, curriculum and driver training lesson should be improved to create better attitude among drivers. Drivers also should change their driving attitude by becoming safe drivers and exhibiting defensive driving skills on the road.
\end{abstract}

\section{Introduction}

Anger is an emotion that is commonly experienced while driving but angry drivers present a problem on the roads. Driver anger was conceptualised as a personality trait related to an individual's underlying predisposition for anger, but specific to road situations [1]. This is because driver anger has been identified as a predictor of traffic crashes and precursor to behaviors that increase the likely hood of traffic crashed [2]. Furthermore, research found that those individuals who reported high levels of anger are more likely to be outwardly aggressive [3]. Therefore driver anger also leads to aggressive driving behaviours [4]. Angry drivers, however, can become aggressive and tend to incorporate a higher level of risk-taking into their driving style [5]. Studies have shown that significant relationship exist

* Corresponding author: kamardin@uthm.edu.my 
between driving anger and crash related conditions such as losing control of their vehicle, losing concentration, speeding, tailgating, near misses and moving violations (tickets) $[4,6]$. While driving, high anger drivers experience more anger triggers, frequent and intense anger, hostile thinking, aggression, risky behavior, and some crash related conditions than low anger drivers [7].

For these reasons, it is important to understand what makes drivers become angry and how serious their anger is in that situation. Many researchers often use the Driving Anger Scale (DAS) was developed by Deffenbacher [1] to measure individual's "trait driving anger" which is their propensity to become angry across a number of different driving situations. DAS produced six factors relating to the types of situations likely to provoke anger which consists: discourtesy, hostile gestures, traffic obstruction, slow driving, police presence and illegal driving. These six factors have been reported to show generally positive correlations with each other, which indicate a general trend for driving anger in addition to independent reactions to different types of situation $[1,8]$. Hence, the objectives of this study were to identify which situations are major contributing factors that cause the anger of drivers and evaluate the Driver Anger Scale (DAS). Another objective for this study was to analyze the relationship between driver anger with the factors of DAS.

\section{Material and methods}

This survey was carried out in district of Batu Pahat, Johor. Batu Pahat was chosen as the location of study because it represents the region where the highest number of road accidents were recorded in Johor [9].

\subsection{Instrument and measurement}

This study was conducted using the cross sectional study method. Questionnaires were used distribute to car drivers in Batu Pahat and interviews were conducted with respondents. The questionnaire was developed based on previous studies as in $[1,10]$ and divided into three parts. In the first part, background information of respondents was collected. This included gender, age, race, status of marriage, and occupation of respondent. The second part of the questionnaire involves the experience of driving among respondents, which included type of driving license, duration of driving experience, frequency of driving, distance of driving, traffic accident history, traffic ticket history and frequency of drivers feeling angry while driving. The last part of the questionnaire is Driving Anger Scale (DAS) section, which describes situations that provoke driver anger. Participants were asked to rate how angry they would become if they came across each situation. Ratings were given based on a five point Likert scale ( $1=$ not angry, $2=$ slightly angry, $3=$ angry, $4=$ very angry $5=$ extremely angry). A pilot study was conducted to determine the reliability of the questionnaire. 25 sets of questionnaire were distributed to respondents and the study yieled an Alpha Cronbach test value of 0.907 , which showed that questionnaire was highly reliable.

\subsection{Sample size and location of study}

The sample size of this study included 250 respondents randomly selected among car drivers in Batu Pahat, Johor and these involved drivers who were willing to complete the survey and be interviewed. The duration for data collection was two months, beginning from March 2015 and ending in May 2015. 


\subsection{Statistical analysis tool}

The Statistical Package for the Social Sciences (SPSS) version 20.0 was used to analyse the dataas analyze through the application of statistical methods such as descriptive analysis, chi-square test, correlation test and multiple regression analysis.

\section{Results and discussions}

A total of 250 respondents completed the questionnaire. The following subsections detail the statistical analyses conducted on the data gathered.

\subsection{Descriptive analysis}

From this study, there were 250 respondents who drove cars in Batu Pahat, Johor. Majority of them were male (52.4\%). Most of them were aged between 26 to 35 years old $(28.8 \%)$. Besides that, more than half of the respondent were married (58.8\%) and over a quarter of the work in the government sector (26.4\%). Most drivers have full car driving license $(91.2 \%)$ and $28.8 \%$ of the respondent have driving experience 15 years and more. Furthermore, large number of repondent (69.2\%) drove their cars everyday, with $38 \%$ of them driving for a distance of between $11 \mathrm{~km}$ and $20 \mathrm{~km}$. $42.8 \%$ of them admitted to receiving traffic ticket between one and five times and while $60 \%$ of them were involved in road accident (Table 1).

Table 1. Respondent Demographic

\begin{tabular}{lcc}
\hline \multicolumn{1}{c}{ Respondents } & Frequency & $\begin{array}{c}\text { Percentage } \\
(\%)\end{array}$ \\
\hline 1. Gender & 131 & 52 \\
Male & 119 & 48 \\
Female & & \\
2. Age (years) & 72 & 29 \\
Below 25 & 51 & 20 \\
26-35 & 55 & 22 \\
36-45 & 72 & 29 \\
46 and above & & \\
3. Profesion & 42 & 19 \\
Self-employed & 66 & 26 \\
Government Sector & 47 & 19 \\
Private Sector & 60 & 24 \\
Student & 35 & 14 \\
Others (unemployed) & & \\
4. Licenses & 228 & 91 \\
Competent (Class D) & 19 & 19 \\
Probationary (Class P) & 3 & 1 \\
Learner (Class ) & & \\
5. Experience (years) & 50 & 20 \\
Less than 5 & 62 & 25 \\
5-10 & 66 & 26 \\
11-15 & 72 & 29 \\
15 above & & \\
& & \\
\hline
\end{tabular}




\begin{tabular}{lcc}
\hline 6. Driving distance $(\mathrm{km})$ & & \\
Less than 2 & 24 & 10 \\
$2-10$ & 84 & 34 \\
$11-20$ & 95 & 38 \\
20 above & 47 & 19 \\
7. Traffic Summons & 107 & 43 \\
1 time & 89 & 36 \\
2-5 times & 48 & 19 \\
6-10 times & 6 & 2 \\
Over 10 times & & \\
8. Accident Involved & 151 & 60 \\
Yes & 99 & 40 \\
No & &
\end{tabular}

\subsection{Driver anger scale (DAS) analysis}

For the purpose of identifying the major factors that contribute to driver anger while driving, the average mean score and standard deviation of frequently angry driver and factors of Driving Anger Scale (DAS) showed in Table 2. The average score mean for frequently angry driver was rated $4.25(\mathrm{SD}=1.15)$. It can be said that the most frequently angry drivers' score were more than 4 out of 7 to that of quite often angry drievr, seeing that the mean score were closer to the score of always angry driver. From the six factors causing driving anger, discourtesy was rated as the most anger provoking with an average score mean of $3.76,(\mathrm{SD}=.64)$. The situations that were found to intensely provoke driver anger weres "Someone did not give signal to change lane" and "Someone takes the car parking spot you were waiting for". This results were statistically similar to the subscale mean obtained for Malaysia sample [9]. Furthermore, the factor that was found to be least provoking was police presence, which had the lowest average anger rating $(\mathrm{M}=2.08$, $\mathrm{SD}=0.78$ ) of the six factors. This finding is inline with a previous study that reported, the presence of police did not evoke any appreciable amounts of anger amongst their sample of Turkish and Malaysian drivers [11,12].

Table 2. Average means and standard deviation of driver anger and DAS factors

\begin{tabular}{cccc}
\hline Sub scale factor & No. item & $\begin{array}{c}\text { Average } \\
\text { mean score }\end{array}$ & $\begin{array}{c}\text { Standard } \\
\text { deviation (SD) }\end{array}$ \\
\hline Frequently angry driver & 1 & 4.25 & 1.15 \\
Discourtesy & 4 & 3.76 & 0.64 \\
Hostile gesture & 4 & 3.44 & 0.97 \\
Slow driving & 4 & 3.30 & 0.69 \\
Police presence & 4 & 2.08 & 0.78 \\
Traffic obstruction & 4 & 3.17 & 0.66 \\
Illegal driving & 4 & 3.30 & 0.73 \\
\hline
\end{tabular}

Table 3 shows that summary of driving anger by age, gender, driving experience, driving distance, traffic crash involvement and receiving traffic ticket. By using chi- square test, it was found that age, driving experience, driving distance, traffic crash involvement and receiving traffic ticket were significant $(p<0.05)$ influenced driving anger. It can be concluded that age, driving experience, driving distance, traffic crash invovlement and receiving traffic ticket have relative order with DAS. 
The results of chi-square test aalso found that young drivers (57.7\%) were more likely to be angry than older drivers. This findings is comparable to a previous study that showed young drivers are more likely to display anger and aggression [13,14]. Moreover, less experienced drivers $(47.7 \%)$ were more likely to be angry than more experienced drivers. Drivers driving for more than $10 \mathrm{~km}(54.2 \%)$ was also found to cause a driver to be more likely angry while driving. These result can linked to a previous study that found some relationship between annual mileage and anger [13]. Besides that, this study also found that drivers who had prior experience of being involved in traffic crashes $(60.9 \%)$ and those who had received traffic tickets $(53.4 \%)$ were more likely to be angry. These results are in line with a previous research [8], which stated that drivers who reported minor losses of control and those who reported receiving a recent traffic ticket had reliably higher tendencies to become angry.

Table 3. Summary chi-square test result for descriptive variable with DAS

\begin{tabular}{ccccc}
\hline Descriptive variable & Chi squre $\left(\chi^{\mathbf{2})}\right.$ & df & $\begin{array}{c}\text { Significance } \\
(\mathbf{p}<\mathbf{0 . 0 5})\end{array}$ & Result \\
\hline Age & 9.172 & 1 & 0.002 & Yes \\
Gender & 0.227 & 1 & 0.634 & No \\
Driving experience & 5.058 & 1 & 0.025 & Yes \\
Driving distance & 5.104 & 1 & 0.024 & Yes \\
Involved traffic crashed & 25.532 & 1 & 0.000 & Yes \\
Traffic ticket & 5.315 & 1 & 0.021 & Yes \\
\hline
\end{tabular}

\subsection{Correlation analysis}

The correlation coefficient is a statistical value that measures the strength of relationship between one or more variables [13]. Table 4 shows the results of the for correlation between driver anger and the DAS factors.

Table 4. Correlation coefficient for DAS factors

\begin{tabular}{|c|c|c|c|c|c|c|c|}
\hline & $\begin{array}{l}\text { Driver } \\
\text { anger }\end{array}$ & Discourtesy & $\begin{array}{l}\text { Hostile } \\
\text { gesture }\end{array}$ & $\begin{array}{l}\text { Slow } \\
\text { driving }\end{array}$ & $\begin{array}{l}\text { Police } \\
\text { presence }\end{array}$ & $\begin{array}{l}\text { Traffic } \\
\text { obstruction }\end{array}$ & $\begin{array}{l}\text { Illegal } \\
\text { driving }\end{array}$ \\
\hline $\begin{array}{l}\text { Driver } \\
\text { anger }\end{array}$ & 1 & & & & & & \\
\hline Discourtesy & $.470 * *$ & 1 & & & & & \\
\hline $\begin{array}{l}\text { Hostile } \\
\text { gesture }\end{array}$ & $.253 * *$ & $.478 * *$ & 1 & & & & \\
\hline $\begin{array}{l}\text { Slow } \\
\text { driving }\end{array}$ & $.227 * *$ & $.391 * *$ & $.449 * *$ & 1 & & & \\
\hline $\begin{array}{l}\text { Police } \\
\text { presence }\end{array}$ & .016 & .097 & $.220 * *$ & $.317 * *$ & 1 & & \\
\hline $\begin{array}{l}\text { Traffic } \\
\text { obstruction }\end{array}$ & $.249 * *$ & $.276^{* *}$ & $.215^{* *}$ & $.483 * *$ & $.440 * *$ & 1 & \\
\hline $\begin{array}{l}\text { Illegal } \\
\text { driving }\end{array}$ & -.003 & .048 & .046 & .096 & $.184 * *$ & $.306^{* *}$ & 1 \\
\hline
\end{tabular}

**. Correlation is significant at the 0.01 level (2-tailed). 
It was found that discourtesy wase highly correlated with driver anger, showing a positive linear relationship and significant $(\mathrm{p}<0.01)$. Meanwhile, hostile gesture, slow driving and traffic obstruction were found to be positively correlated and significant $(p<0.01)$ with driver anger. It is can be concluded that four out of six factors of DAS had strong and significant relationship with driver anger. Based on a previous study the DAS was found to be related to trait anger scale with a strong correlation coefficient $[10,13]$. Another research, Yasak and Esivol [11] stated that the correlations between anger symptoms and the six factors of DAS have positive correlation and were significant among the factor DAS, except for illegal driving.

\subsection{Multiple Regression Analysis}

Table 5 shows the model summary of multiple regression analysis conducted for driver anger. Model 1, yeilded a $\mathrm{R}^{2}$ of .250 which means that a $25 \%$ change in the independent variable (factor of DAS) due to the dependent variable (driver anger).

Table 5. Summary of multiple regression toward driver anger and factor of DAS

\begin{tabular}{llccc}
\hline Model & $\mathbf{R}$ & $\mathbf{R}^{2}$ & $\begin{array}{l}\text { Adjusted } \\
\text { R square }\end{array}$ & $\begin{array}{c}\text { Standard Error of the } \\
\text { Estimate }\end{array}$ \\
\hline 1 & $.500^{\mathrm{a}}$ & .250 & .232 & 1.005 \\
\hline
\end{tabular}

Table 6 shows that the summary of ANOVA analysis for driver anger. It was found that a significant relationship $(\mathrm{p}<0.05)$ exists between the independent variable (factor of DAS) with the dependent variable (driver anger).

Table 6. Summary of ANOVA analysis for driver anger with factor of DAS

\begin{tabular}{lcccccc}
\hline Model & & Sum of square & df & Mean & F & Sig. \\
\hline \multirow{3}{*}{1} & Regression & 81.832 & 6 & 13.639 & 13.511 & $.000^{\mathrm{b}}$ \\
& Residual & 245.292 & 243 & 1.009 & & \\
& Total & 327.124 & 249 & & & \\
\hline
\end{tabular}

Table 7 show the results of a regression analysis conducted on the factor of DAS as the independent variable and driver anger as the dependent variable. It was determined that the factor of discourtesy and traffic obstruction have a significant relationships $(p<0.05)$ with driver anger. For this model, the discourtesy factor showed the highest beta value $(\beta=.412$, $\mathrm{t}=6.257, \mathrm{p}<.05)$ which concludes that the discourtesy factor exerts the greatest influence on a driver become angry while driving.

\section{Conclusion}

In conclusion, this study has found that the major contributing factors to driver anger were discourtesy, hostile gesture, slow driving, illegal driving and traffic obstruction.The, the relevant authorities should be give more attention to these driver misbehaviours in order to curtail driver anger or road rage. Apart from that, this study also found that young drivers, less experienced drivers, long distance driving, drivers with prior involve in road accidents 
and drivers who have received traffic ticket were more likely feel angry while driving. In addition, discourtesy was found to have positive linear relationship and was significantly influential towards driver anger. Discourtesy was also found to be the greatest contributing factor in causing drivers to become angry while driving. In order to overcome this issue, the authorities and enforcement teams should be more focused on minimising discourtesy behaviour among drivers. Campaign via mass media can be instrumental in highlighting the types of good driving behaviour, advocating tolerance in driving style and showing the negative impacts of engaging in discourteous driving behaviour.

Table 7. Regression coefficient

\begin{tabular}{|c|c|c|c|c|c|c|}
\hline & \multirow[t]{2}{*}{ Model } & \multicolumn{2}{|c|}{$\begin{array}{l}\text { Unstandardized } \\
\text { coefficient }\end{array}$} & \multirow{2}{*}{$\begin{array}{c}\text { Standardized } \\
\text { coefficient }\end{array}$} & \multirow{2}{*}{ t } & \multirow{2}{*}{ Sig. } \\
\hline & & B & $\begin{array}{r}\text { Std. } \\
\text { Error }\end{array}$ & & & \\
\hline & (Constant) & .918 & .495 & & 1.853 & .065 \\
\hline \multirow[t]{6}{*}{1} & Discourtesy & .738 & .118 & .412 & 6.257 & .000 \\
\hline & Hostile gesture & .053 & .080 & .045 & 0.660 & .510 \\
\hline & Slow driving & -.016 & .117 & -.010 & -0.141 & .888 \\
\hline & Traffic obstruction & .344 & .124 & .197 & 2.774 & .006 \\
\hline & Illegal driving & -.101 & .092 & -.065 & -1.103 & .271 \\
\hline & Police presence & -.155 & .093 & -.105 & -1.663 & .098 \\
\hline
\end{tabular}

The authors would like to thank Universiti Tun Hussein Onn Malaysia (UTHM) for funding this study under the Multidisciplinary Research Grant (MDR) Vot U090 and Smart Driving Research Center (SDRC), Faculty of Civil and Environmental Engineering for support and providing facilities to accomplish the study.

\section{References}

[1] J.L. Deffenbacher, E.R. Oetting, R.S. Lynch, Development of a driver anger scale, Psychological Reports, 74, 83-91 (1994)

[2] A.N. Stephens, J.A. Groeger, Anger-congruent behaviour transfers across driving situations, Cognition and Emotion, 25, 1423-1438 (2011)

[3] R. Lawton, A. Nutter, A comparison of reported levels and expression of anger in everyday and driving situations, British Journal of Psychology, 93, 407-423 (2002)

[4] J.L. Deffenbacher, R.S. Lynch, L.B. Filetti, E.R. Dahlen, E.R. Oetting, Anger, aggression, risky behaviour, and crash-related outcomes in three groups of drivers Behav. Res. Ther, 41, 333-349 (2003)

[5] J.L. Deffenbacher, R.S. Lynch, E.R. Oetting, D.A. Yingling, Driving anger: Correlates and a test of state-trait theory, Personality and Individual Differences, 31, 1321-31 (2001)

[6] T. Lajunen, D. Parker, Are aggressive people aggressive drivers? A study of the relationship between self-reported general aggressiveness, driver anger and aggressive driving, Accident Anal. Prev., 33, 243-255 (2001)

[7] M.J.M. Sullman, A.N. Stephens, D. Kuzu, The expression of driving anger amongst Turkish taxi drivers, Accident Analysis Prevention, 56, 42-50 (2013) 
[8] J.L. Deffenbacher, Angry drivers: Characteristics and clinical interventions, Revista Mexicana de Psicologia, 26 (1), 5-16, (2009)

[9] Polis Diraja Malaysia, Statistik kemalangan jalan raya 2011 di daerah Batu Pahat, Batu Pahat, Balai Polis Trafik Batu Pahat, (2011)

[10] M.J.M. Sullman, A.N. Stephens, M. Yong, Driving anger in Malaysia, Accident Analysis and Prevention, 71, 1-9 (2014)

[11]Y. Yasak, B. Esiyol, Anger amongst Turkish drivers: Driving anger scale and its adapted long and short version, Safety Science, 47, 138-144 (2009)

[12]K. Ambak, R. Ismail, R.A. Abdullah, A.A. Latiff, M.E. Sanik, Application of technology acceptance model in predicting behavioral intention to use safety helmet reminder system, Research Journal of Applied Sciences, Engineering and Technology, 5 (3), 881-888 (2013)

[13] M.J.M. Sullman, A.N. Stephens, A comparison of the driving anger scale and the propensity for angry driving scale, Accident Analysis Prevention, 58, 88-96 (2013)

[14] M.B. Ahmed, K. Ambak, A. Raqib, N.S. Sukor, Helmet usage among adolescent in rural road from the extended theory of planned behavior, Journal of Applied Sciences, 13, 161-166 (2013) 